\title{
Linking marine conservation and Indigenous cultural revitalization: First Nations free themselves from externally imposed social-ecological traps
}

\author{
$\underline{\text { Lauren E. Eckert }}^{1}, \underline{\text { Natalie C. Ban }}^{2}, \underline{\text { Snxakila-Clyde Tallio }}^{3}$ and Nancy Turner $^{2}$
}

\begin{abstract}
Continuity of coastal Indigenous cultures relies on healthy ecosystems and opportunity to fulfill cultural practices. Owing to resource stewardship practice over millennia, Indigenous nations possess Indigenous knowledge that positions them as leaders in contemporary resource management. However, Indigenous peoples possibly face social-ecological traps, situations in which feedbacks between social and ecological systems result in an undesirable state, that are challenging to overcome. Centuries of compounding colonization and environmental degradation have negatively impacted Indigenous knowledge and culturally mediated stewardship practices. Our partnership, comprising academics and four First Nations on the Central Coast of British Columbia, Canada, mobilized information from semistructured interviews with knowledge holders to explore Indigenous knowledge of a culturally important but vulnerable species, yelloweye rockfish (Sebastes ruberrimus). We analyzed interviews and discovered evidence of an extant but transcendable social-ecological trap. The emergent themes represent an exploration beyond our original project goals and research questions. Our study revealed that external forces of colonization, i.e., via forced assimilation, and species declines created a socialecological trap. However, participants ubiquitously described stewardship principles, and noted ongoing cultural revitalization efforts, active recovery of depleted species, and reassertion of Indigenous management rights as ways they are rebelling against, and overcoming, the trap. Although the framing of a social-ecological trap may be perceived as diminishing the authority of Indigenous governance systems, we found the opposite to be true. Despite external pressures, coastal First Nations are reasserting cultural and management rights and shaping their futures. We suggest that ongoing Indigenous cultural renewal and ecosystem recovery in the face of the historically entrenched trap be supported through recognizing and implementing inherent Indigenous marine management rights. The social-ecological trap described here differs from others in the literature in that the creation of the trap was external; moving beyond it is happening through internal, i.e., led by the First Nations, efforts.
\end{abstract}

Key Words: fisheries; Indigenous knowledge; marine conservation; social-ecological trap; traditional ecological knowledge; yelloweye rockfish

\section{INTRODUCTION}

Continuity of coastal Indigenous cultures relies on healthy ecosystems and species, and the ability to carry out cultural practices (Turner et al. 2013a, Cisneros-Montemayor et al. 2016). Over thousands of years of observation and culturally transmitted learning, Indigenous peoples developed complex conservation strategies to steward marine resources (Berkes et al. 2000, Turner and Berkes 2006, Berkes 2012). Indigenous governance principles are specific and place-based, yet commonalities exist globally. For example, many Indigenous peoples developed customary marine tenures whereby individuals, families, or communities hold stewardship responsibility for particular areas or resources (Johannes 1998, 2002), although specific implementation varies (Johannes 1978, Colding and Folke 2001, Cinner and Aswani 2007). Such practices, passed down generationally by means of oral stories, ceremonies, art and dance, taboos, and other cultural elements, constitute part of the knowledge, practice, and belief complex of Indigenous peoples (Berkes 2012). Indigenous knowledge (IK) is one phrase used to define this place-based and evolving knowledge complex.

The research described herein on marine resource management issues, carried out in partnership with First Nations in British Columbia (B.C.), Canada, led us to reflect on the interactions between declining marine resources and reduced prevalence of Indigenous management compared to precolonial times. In the last century, the combined impacts of colonization and degradation of marine ecosystems have undermined management practices and IK of Indigenous peoples (Smith 1999, Adams and Mulligan 2003, Berkes 2012, Turner et al. 2013b), potentially creating social-ecological traps. A social-ecological trap refers to situations in which "feedbacks between social and ecological systems lead toward an undesirable state that may be difficult or impossible to reverse" (Cinner 2011:835). Human responses to trap drivers often intensify the trap, exacerbating an undesirable state (Boonstra et al. 2016).

The concept of social-ecological traps has been used in numerous case studies to better understand how feedbacks between ecological and social systems push ecological and/or social communities beyond sustainable thresholds to new, undesirable states (Hughes et al. 2005, Steneck 2009, Cinner 2011, Boonstra and De Boer 2014, Boonstra et al. 2016). In other parts of the world, situations of poverty or overpopulation, where socioeconomic factors drive humans to extirpate key resources, thus entrenching themselves deeper in poverty, are common social-ecological traps. For example, in coral reef systems of East Africa, impoverished human communities respond to resource depletions by intensifying harvesting efforts to attain enough food to survive, thereby perpetuating poverty (Cinner 2011, Long and Lake 2018). High value of hyper-abundant resources, like the Maine lobster (Homarus americanus), can create a gilded socialecological trap, in which removal of key marine predators and market forces combine to extirpate some resources, resulting in decreases in ecosystem diversity, and lack of economic, social,

${ }^{1}$ University of Victoria Department of Geography, ${ }^{2}$ University of Victoria School of Environmental Studies, ${ }^{3}$ Ancestral Governance Project, Nuxalk Nation 
and ecological resilience (Steneck et al. 2011). Other socialecological traps include instances in which local or customary environmental management systems are replaced or superseded by centralized top-down governance schemes, which alienate local populations from resource management responsibilities and are often less nuanced or regionally relevant (Cinner 2011, Long and Lake 2018). Notably, Boonstra et al. (2016) have developed a typology that encapsulates known human responses to socialecological traps, which include, "(1) Thick conformity; (2) Thin conformity; (3) Resignation; (4) Innovation; and (5) Rebellion." (Boonstra et al. 2016:887)

Social-ecological traps emerge from historical dynamics (Boonstra and De Boer 2014, Boonstra et al. 2016). Some authors have explored the historical influences that drive these traps (e.g., Long and Lake 2018), yet improved understanding of how complex historical, social, and ecological factors combine to create modern social-ecological traps remains a knowledge gap. Boonstra and De Boer (2014) argue that social-ecological traps are not conditions that suddenly trap social and ecological systems in an undesirable state, but rather consist of pathdependent processes that occur gradually or in stages. Thus, understanding the complexities of historical social-ecological trap dynamics is important for gaining insights into how such traps might be mitigated (Boonstra and De Boer 2014, Boonstra et al. 2016, Long and Lake 2018).

The Central Coast of B.C. is faced with a different socialecological trap than those typically described in the literature. Colonization and environmental degradation are historical processes (Boonstra and De Boer 2014, Long and Lake 2018) particularly important when considering Indigenous socialecological systems because they perpetuate combined impacts on Indigenous knowledge and culture. These impacts exacerbate unsustainable resource management by colonial governments, creating further consequences for Indigenous lifeways. Colonization includes systemic repression of Indigenous peoples (via forced assimilation, religious conversion, and displacement, among others) to dismantle the cultural and generational means by which Indigenous peoples transmit knowledge (Smith 1999, Environics Research Group 2008, United Nations 2008). For example, in Canada, the residential schooling system implemented from the mid-1800s until 1996 widely and profoundly impacted the transmission of culture and IK (Royal Commission on Aboriginal Peoples 1996). For most of that period, Indigenous governance structures, e.g., potlatches, and overseeing sustainable fishing technologies such as fish traps and weirs, were illegal, preventing the open practice of cultural resource management and effective governance.

Damage to Indigenous cultures, languages, and IK can be difficult to reverse because of their oral nature (Berkes 2012). Declines in marine species resulting from industrial-scale fishing (Slaney et al. 1996, Pauly et al. 1998, Moody 2008, Worm et al. 2009, Department of Fisheries and Oceans Canada 2015), made possible by declaring Indigenous management illegal, further affects cultural practices (e.g., stewardship, management, subsistence fishing), Indigenous governance structures, and IK, creating a social-ecological trap. Forced into a state of dormancy, Indigenous knowledge and cultural practices are at risk of disappearing, thus perpetuating the effects of colonization and environmental degradation. This trap is different than many of those often described elsewhere in the literature in that it was created by historical and external processes of colonization and industrial-scale exploitation, which were imposed upon Indigenous peoples.

We examine whether the framework of social-ecological traps can point toward specific ways in which undesirable social-ecological states might be mitigated. The research project we describe as an example is Indigenous driven and ongoing. We (LEE, NCB, NT) were approached by four First Nations, as many Indigenous nations are called in Canada, through the Central Coast Indigenous Resource Alliance (CCIRA) to jointly develop applied research on IK and marine resource management; SCT is a member of the Nuxalk Nation whose expertise and scholarship aligned him well to contribute to project goals and this manuscript. Collectively, CCIRA-member Nations identified a focal species of ecological and cultural concern, yelloweye rockfish (Sebastes ruberrimus), to integrate scientific and Indigenous knowledge into local management plans. Our role as researchers (LEE, NCB, NT) was to accomplish the goals identified by partnering Nations to strengthen their marine management plans. The original goal of the study was to quantify change in yelloweye rockfish catches and abundance over time in order to inform management locally and federally, while upholding the value of Indigenous and local ecological knowledge (Eckert et al. 2018). Although important for informing conventional fisheries management, the resulting publication (Eckert et al. 2018) did not sufficiently reflect the cultural context, knowledge, and changes described by Indigenous knowledge holders, nor capture the Nations' profound cultural connection to yelloweye rockfish and other key marine resources. Here we summarize unexpected qualitative aspects of the study, using the lens of a social-ecological trap. By focusing on the interviews that asked knowledge-holders about changes to yelloweye rockfish, as per the original goal of this research, we address the following questions: (1) Is there evidence of a social-ecological trap leading to damage of IK?; (2) If a social-ecological trap exists, what factors characterize it?; (3) Are there opportunities to escape from the social-ecological trap, and if so, what are they?

\section{METHODOLOGY}

\section{Case study: Central Coast of B.C., Canada}

We partnered with Central Coast First Nations of B.C. (Wuikinuxv, Heiltsuk, Kitasoo/Xai'xais, and Nuxalk Nations, with populations ranging from roughly 80-1500 individuals; Fig. 1) in the productive temperate marine systems ranging from exposed offshore islands to sheltered fjords and inlets. Within the study area, Indigenous peoples have relied on marine resources, including fish, shellfish, marine mammals, and marine algae, for thousands of years. These resources were, and continue to be, embedded within daily life, culture, ceremony, and oral stories (Chapin et al. 2010, Berkes 2012). Like many Indigenous peoples globally, Central Coast First Nations developed sophisticated management techniques, enabling sustainable use (Turner et al. 2000, Berkes 2012, Turner 2014). For example, First Nations actively monitor salmon species abundance, manage and manipulate waterways through which they spawn, and selectively harvest them based on size, gender, abundance, and season (Butler and Menzies 2007, Thornton et al. 2015). Tidal traps (Menzies 
Fig. 1. Map of study region. Bella Bella is home to the Heiltsuk Nation, Bella Coola to the Nuxalk Nation, Wuikinuxv to the Wuikinuxv Nation, and Klemtu to the Kitasoo/Xai'Xais Nation. The combined traditional territories of the four member Nations are depicted.

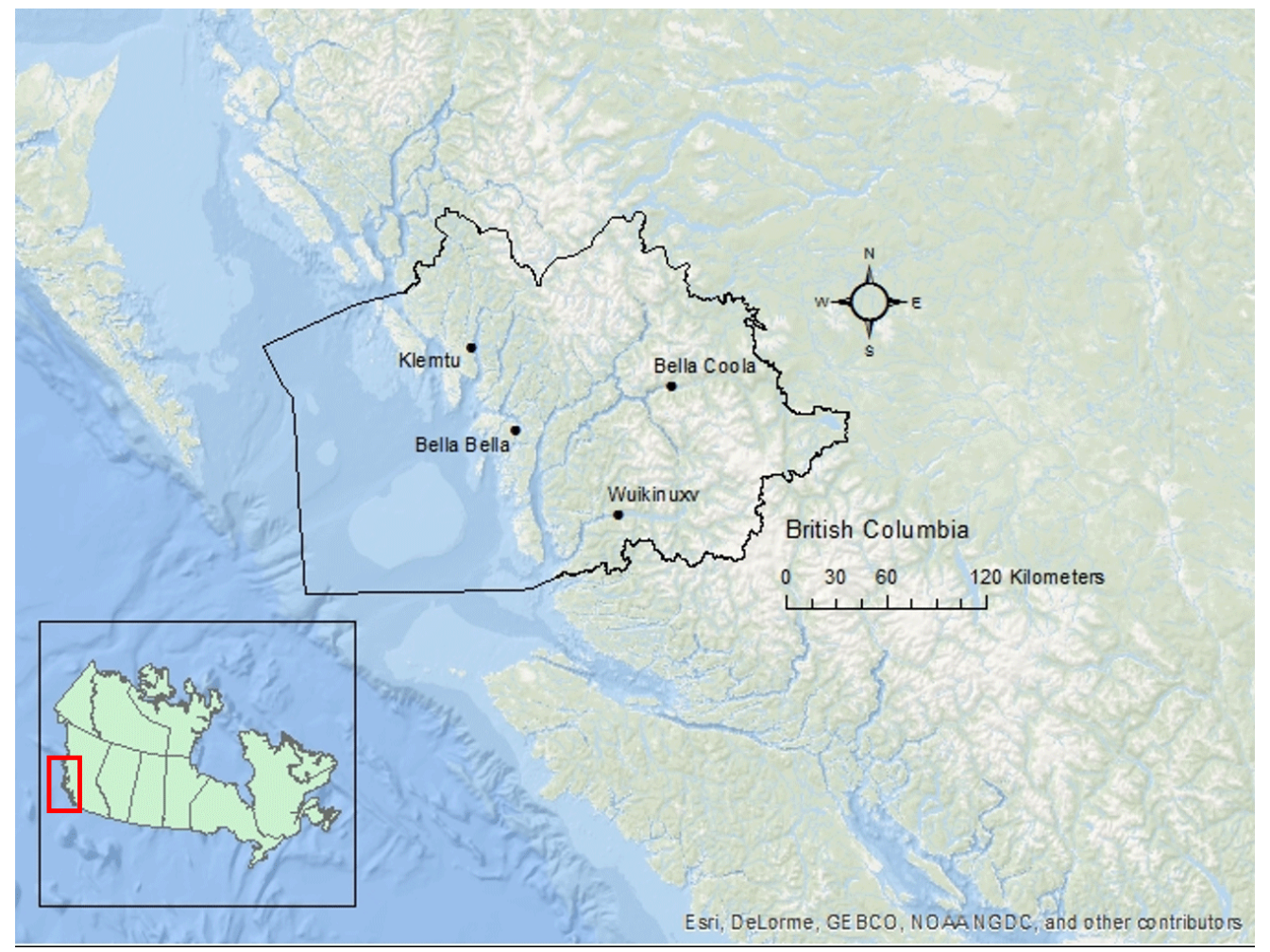

and Butler 2007) and clam gardens (Lepofsky and Caldwell 2013, Groesbeck et al. 2014) are salient examples of conservationoriented harvesting and enhancement strategies. More generally, customary marine tenure systems are documented (Pinkerton 1994, Turner and Berkes 2006, Matthews and Turner 2017) as a means for managing important marine resources.

\section{Research process}

The four First Nations whose management goals led to this project reached out to us through the CCIRA with an interest in consolidating their IK and local ecological knowledge (LEK) regarding yelloweye rockfish. We codeveloped study methodologies and questionnaires, as well as research protocol agreements, with each of the four partnering First Nations, and started the project with community workshops to introduce the proposed research concept and invite knowledge holders to participate. After the workshops and with community collaboration, we conducted semistructured interviews with local knowledge holders, transcribed them, analyzed the information, and followed up with additional workshops to share preliminary results. We also followed up with interviewees, and provided participants transcripts of their interviews wherever feasible.

\section{Semistructured interviews}

We chose a semistructured interview method to retain conversational rapport with knowledge holders and allow for new information to arise spontaneously while ensuring that key questions were addressed (Huntington 2000). Interviews followed the life histories of participants as they related to experiences fishing yelloweye rockfish, and included questions about changes to this species, local environments, and the importance of marine resources to culture (Table 1; see Eckert et al. 2018 for details). In each of the four Nations, stewardship directors and project partners suggested interview participants based on their fishing experience ( $>20$ years of experience, and often elders), and participants could also self-identify based on interest in the project (subject to the experience threshold). Following initial interviews with key knowledge holders, we utilized a snowball sampling method to identify additional participants (Huntington 2000). Participants provided their consent at the onset of interviews, which lasted about 1-3 hours; all were audio recorded for transcription. Although the primary focus of interviews was to assess changes to size and abundance of yelloweye rockfish, the impacts of colonialism and industrial-scale resource extraction (especially fisheries) were prevalent topics throughout interviews. We thus explored the theme of social-ecological traps after the interviews were transcribed.

\section{Analysis}

Transcribed interviews were analyzed for common themes, which we coded into coarse (e.g., harvesting and preparation practices, perceived threats to marine resources, stewardship principles, etc.) and detailed (e.g., historic means of rockfish preparation, impacts of overfishing, etc.) categories for qualitative analysis. Systematic coding of answers regarding stewardship strategies, cultural value 
Table 1. Examples of questions raised in the semistructured interview questionnaire and corresponding social-ecological trap themes analyzed.

\begin{tabular}{|c|c|}
\hline Examples of Questions & Function \\
\hline How old were you when you first started fishing? & Determine the characteristics of the social-ecological trap. \\
\hline $\begin{array}{l}\text { What was the largest yelloweye rockfish (Sebastes ruberrimus) you } \\
\text { remember harvesting? }\end{array}$ & Determine the characteristics of the social-ecological trap. \\
\hline $\begin{array}{l}\text { Do you know any traditional stories about the management of yelloweye } \\
\text { rockfish? }\end{array}$ & Determine the characteristics of the social-ecological trap. \\
\hline Who taught you to fish? & Determine the characteristics of the social-ecological traps \\
\hline $\begin{array}{l}\text { Do you have concerns for the future of marine resources, i.e., beyond } \\
\text { yelloweye rockfish? }\end{array}$ & Determine opportunities for moving beyond the social-ecological trap. \\
\hline Do you have cultural concerns for the future? & Determine opportunities for moving beyond the social-ecological trap. \\
\hline $\begin{array}{l}\text { What solutions do you see to the problems you've described, e.g., to } \\
\text { declining abundance or size of marine species, cultural concerns, etc.? }\end{array}$ & Determine opportunities for moving beyond the social-ecological trap. \\
\hline
\end{tabular}

of rockfish, etc., was performed through NVivo software processing (NVivo qualitative data analysis software; QSR International Pty Ltd. Version 10, 2012).

To gain insight into the existence of a social-ecological trap involving yelloweye rockfish, we analyzed responses to questions about current and past harvesting strategies, and stories or stewardship values for this species (Table 1). During interviews, we provided opportunities for participants to expand on their ideas for actions and approaches that would alleviate the problems and bring them hope, both for their culture and for local resources such as yelloweye rockfish. Finally, we engaged stewardship directors and other leadership from the four First Nations in the interpretation of results and in the direction of this manuscript.

\section{RESULTS}

Forty-three individuals participated in semistructured interviews throughout our project (May 2015-May 2016). Of those, 83\% were men and $17 \%$ women. Fourteen participants identified themselves as Kitasoo/Xai'xais, 14 as Heiltsuk, 7 as Wuikinuxv, and 8 as Nuxalk. Participants ranged in age from 27 to 88 , with an average age of 61 ; we estimated ages in the case of 12 participants who did not disclose this information.

\section{Characteristics of a social-ecological trap}

We found evidence of a social-ecological trap linked to our questions about yelloweye rockfish throughout all interviews. Participants mentioned the external drivers that created the trap, colonization and industrial fishing, primarily, in almost every interview even though we did not specifically ask about these drivers. Thirty-four percent of participants mentioned the residential schooling system, a key impact of colonialism, when asked about their earliest memories of fishing. In addition, many participants (approximately 60\%) observed and articulated depletions in abundance of key marine resources other than yelloweye rockfish not specifically asked about in interviews (e.g., salmon, eulachon, herring, etc.).

We identified the main drivers of the social-ecological trap as the external factors of colonialism and environmental degradation, in the form of extractive industries, overfishing, etc. (Fig. 2). These drivers combine to trap partnering Nations in a cycle that potentially leads to the muting of IK and decreased implementation of Indigenous stewardship practices. The terms "muting" and "dormancy" were used by some participants and stewardship department staff to describe damage to IK, because these terms highlight that the knowledge is not irreversibly lost. The social impacts of colonialism (implemented by the Canadian federal government in the form of residential schools, illegalization of cultural practices, etc.) resulted in a loss of Indigenous management rights and stewardship capacity. The usurping of these rights allowed industrial fishing to proliferate in territorial waters of coastal First Nations, leading to decreased abundance of marine species (Slaney et al. 1996, Hay and McCarter 2000), many of cultural importance (Moody 2008), and environmental degradation. Decreased abundance of culturally important species, e.g., salmon, eulachon, groundfish, etc., in turn decreased access to resources and harvesting practices; these practices are generationally passed and deeply embedded in local culture and lifeway. A degraded environment and decreased opportunity to practice culturally embedded stewardship strategies may limit the generational retention of IK amongst coastal First Nations. The intentional damage to these knowledge systems, proliferated by the feedbacks between colonialism and environmental degradation, makes the reassertion of IK and management rights even more challenging, continuing the cycle that amplifies the impacts of historical and modern colonialism and extractive industries (Fig. 2).

However, our analysis and experiences indicated that, despite the Canadian federal government's forced assimilation campaign (Short 2003, Environics Research Group 2008), core values and details of culture have been retained, suggesting that the trap is reversible, and in reality is already being overcome. Thus, we suggest that the IK of involved First Nations surrounding yelloweye rockfish has not been lost, but rather the state of muted dormancy into which it was externally thrust is being actively rebelled against.

\section{Evidence of the social-ecological trap}

Here we describe the characteristics of the social-ecological trap, using quotes to demonstrate typical responses (see Table 1 for relevant interview questions). Historically, harvesting and stewardship strategies and lessons were generationally passed by First Nations (Turner et al. 2000, Turner and Berkes 2006, Brown and Brown 2009). Of the 43 participants, 41 (95.3\%) were exposed to fishing by their family members (parents, grandparents, aunts, uncles, etc.). At an early age, they were taught strategies and protocols for fishing yelloweye rockfish and other species, as well 
as fish preparation methods. The two participants who were not taught to fish by a family member felt that they were largely raised in the residential school system, thus their ability to fish with their families was limited greatly. When questioned if his parents taught him important harvesting or stewardship principles, one participant responded, "No, my father never brought me up, the residential school brought me up" (Anonymous 1, May 2015). Several of the participants taught to fish by their families reflected that their experiences together were limited to summers spent away from residential schools.

Fig. 2. The social-ecological trap. On the left, this figure depicts the forces that drove partnering First Nations on B.C.'s Central Coast into a trap, and the interacting forces that perpetuate the trap. On the right, positive interactions generated within First Nations highlight ways to escape the trap.

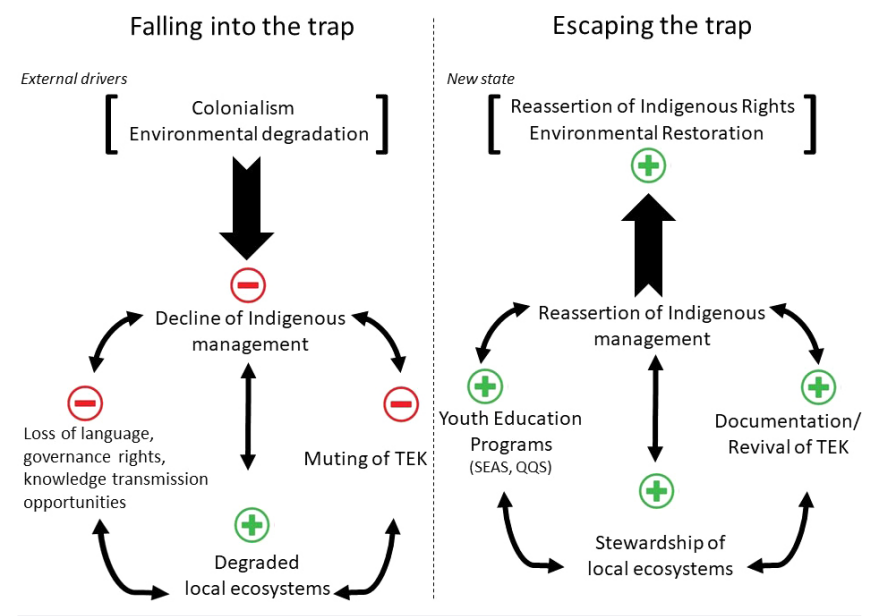

The stewardship principles of First Nations and other Indigenous groups are often embedded within culture via lifeways, oral stories, and ceremony (Turner and Berkes 2006, Berkes 2012, Turner et al. 2013b). We asked participants specifically about traditional stories regarding yelloweye rockfish, and about general stewardship strategies applied to this and other fish. Only two of the 43 participants remembered being told stories about yelloweye rockfish, and only one individual (a coauthor, SCT) was able to recount a story. When asked about his memory of traditional stories, one elder immediately gestured toward the impacts of colonization:

Christianity was really strong, they didn't allow anyone to pass a story to us... There were a lot of masks, totem poles, talking sticks, rattles; they were all here! They were gathered and burned by the Church. Now we're slowly getting it back. (Anonymous 2, June 2015)

Despite a lack of traditional stories that motivated or contextualized sustainable harvesting practices, all participants related a conservation principle when asked about stewardship or management strategies for yelloweye rockfish. All participants shared that they were taught from an early age to "take only what you needed, nothing more" (Anonymous 3, May 2016). One participant explained,

Yeah, [we were taught:] don't over catch, don't get too greedy. Just take what you need. So that's all I've been doing: get enough, go home. When I was younger, it was nothing to go out in one day and get what you need for the whole winter for salmon and you don't have to go out again. Nowadays, you have to go once a week or twice at times, just to get what you need... (Anonymous 4, June 2015)

Others remembered more details surrounding this principle, and its foundation in respect toward critical resources;

The Elders always talked about being respectful, not overharvesting things. It's kind of weird to think about now, but [they] used to talk about how when you catch your first four fish, you're supposed to let your first four fish go. Same thing with berries, when you're picking berries, you're supposed to throw the first four berries behind your back. They always talk about doing that... (Anonymous 5, June 2015)

Some participants related that they were trained from a young age to align their actions with this principle, and others emphasized that the principle is "always something that we teach our younger people." Participants juxtaposed this ingrained principle with the strategies utilized by commercial and recreational harvesters: "We [First Nations fishers] only get enough to eat, we don't take a whole bunch [of fish] like these [commercial fishermen] that take the whole stock" (Anonymous 6, July 2015). Leaving a reproductively viable population for future generations was a key theme of the repeated wasteavoidance principle, as was respecting resources. One elder expanded, "It's like you always hear the elders say, the Creator has given all this to us to look after. It's our duty to look after it." (Anonymous 6, July 2015)

The one participant (and coauthor of this study, SCT) able to relate stories involving traditional use, harvesting, or taboo surrounding yelloweye rockfish was an individual in his late $20 \mathrm{~s}$, who had dedicated his youth and early career to studying the traditional law and ways of the Nuxalk Nation. The yelloweye rockfish story, belonging to the Tallio family, involves the Q'umukwa, whose name literally translates "the wealthy one beneath the Sea" (or "Spirit Chief under the Sea"), who lived in a copper house, adorned in living and painted sea creatures. Bottom-dwelling fish (including large yelloweye rockfish) are painted on the walls of his underwater home. In times of plenty, when the Spirit Chief dances, Q'umukwa sent the yelloweye paintings dancing off the walls of the house, to become living and provide themselves as food in order for the Nuxalk people to survive. Before each species was harvested, the community held a ceremony, reciting "qamxamilaw," to collectively show honor, respect, and gratitude for the fish's contribution to their survival.

Eight participants $(18 \%)$ had personal recollection of, or otherwise knew of, a time when families stewarded designated geographic ocean areas via a customary tenure system, whereby hereditary chiefs steward areas and grant permissions to harvest resources.

[There were] certain areas and families owned those places: clam bay, fish stream, berry picking grounds. Even the medicine, certain areas belonged to a family and you can't just go storming in there and get what you want, you have to ask permission (Anonymous 7, June 2015) 
One participant related the importance of monitoring in tenure systems.

There [were] really strict rules on where you could harvest, and for a long time we had people patrol the rivers and monitor areas and they would dictate whether stocks were low and they would let people know ... (Anonymous 5, August 2015)

Other individuals were aware of former tenure practices, but had not experienced them within their lifetime.

\section{Assessing opportunities to escape the social-ecological trap}

Concerns about the future, and suggestions for moving forward, highlight participants' suggestions for escaping the socialecological trap and were overwhelmingly present throughout interviews when people were asked about improving management of yelloweye rockfish. Of 28 participants, 27 who chose to respond to the question regarding future concerns expressed serious worries for the future of yelloweye rockfish and the ocean ecosystems upon which they rely. Nine respondents were explicitly worried about stock depletions leading to damage of cultural lifeways, food security, or language deterioration. Many individuals indicated that concerns about yelloweye rockfish apply for all resources, reflecting on the reality of interconnectedness.

Well, commercialization [is the biggest threat to future resources] right now. Department of Fisheries (DFO) has not yet come to realize that... we have a circle of life, everything goes in a circle including us, it's connected in one way or another. (Anonymous 9, August 2015)

Two participants expressed fear of losing competency of their Indigenous language, and seven were concerned that the youth of today were disconnected from traditional culture, harvesting practices, and increasingly from traditional foods; television and technology, a lack of access to boats, and residential schools were blamed for this cultural disconnection. One elder lamented the attempted destruction of her Indigenous language:

Language is... I can't believe we're losing it... When I went to [residential] school I had a way of zipping my mouth and not saying a word, not letting anyone know what you are thinking... how [the schools] made it so easy for kids to lose their language, it really hurts. Some people think it's right to speak the white man's language. Why? I don't know. You should be proud of who you are. (Anonymous 10, August 2015)

Regarding decreased access of traditional foods, one participant offered, "They lose their health [when they lose their traditional foods]. They went to residential school and they lost it; when they came back they didn't know how to do it" (Anonymous 11, August 2015). Other interview participants tied their concerns regarding past and future cultural dormancy directly to the impacts of residential schools:

I remember elders, when I was younger... only language was the native [traditional] language. So, I remember some elders trying to tell stories, but they would need someone to translate for them... they said the words [between the two languages] were so different that a lot of the stories were lost through translation. [The next] generation, [many of them] can't tell me a story, can't tell me a song or dance... And I think the products of residential school, didn't really teach them the ways.... None of [language, culture, or stories] were passed on to us as kids, and that was really unfortunate but that's just the way it was... (Anonymous 5, August 2015).

Despite recognizing past and current threats to their marine resources and culture, many participants provided concrete examples of hope and actions leading to ways beyond the trap. Eighteen participants provided suggestions for improving management of marine resources. When asked how to face many of the concerns they expressed for future marine resources, participants $(55 \%)$ called for increased recognition of local management rights and integration of IK into management plans. "We need to be able to control the areas to be able to shut down [fishing in] nurseries for halibut, rock piles for cod, [etc.]" (Anonymous 12, July 2015).

Other participants $(21 \%)$ were hopeful that community revival of culturally based education systems, focused toward youth, was a positive way forward in the face of environmental degradation and colonization. One elder involved in traditional education within her community spoke emphatically about the benefits of educating youth:

If I could change something about the way people live [I'd increase traditional food education] ... because I know one of the things we did have was called "Community Kitchen"... [The founder] did everything with our traditional foods, and she had more and more people coming out to help her cook, because what you'd do is you'd all work together cooking a meal. After you'd cook the meal, complete with dessert, you'd invite some people to come over and eat, and she had that community kitchen going for the whole winter. It was getting really popular, a lot more people were showing up, but things like that are going to have to happen again to generate the interest in people to get them back on track to eating a healthier diet of fish. Teaching kids how to eat, that's one of the things I really hope to try to create some social activities for the communities. [Knowledge holders are] taking kids out seaweed picking from the school, taking them out clam digging. And they have to clean the clams themselves and prepare it for freezing, they freeze it all up. Anything they put away, I think they jarred fish last year, and then they use the stuff that they prepare and preserve, they use it for different activities throughout the school year. (Anonymous 13, August 2015)

Some mentioned particular organizations that support the cultural development of community youth (e.g., The Supporting Emerging Aboriginal Scholars [SEAS] community initiative and the qqs Projects Society). One community leader emphasized the importance of promoting the knowledge of community elders as a means of reviving youth knowledge and the tradition of oral story-telling:

So the way I see it now, is we're trying to bridge that gap between the youth and elders, and so that's what we're trying to do. We only have a handful of elders that really have a true understanding of that important knowledge 
that's been passed on. So I think that things like fishing areas have been passed down, but not things like stories, or songs, or dances. We do still have a few cultural leaders in the community that have helped but we are trying to bridge those gaps right now. (Anonymous 5, August 2015)

An elder expanded on his motivation to enliven culture among community youth,

[I want them to know] the economics of our people. For the younger generation, I want them to know how we lived [off the resources of the land]. At one time, you could live without money and the money was not important. If you put your hand any place in the garden, grab the sand from your garden and put it there... get a dollar bill and put it by its side... Get a match, try burning the sand that produces your vegetables, and burn this hundred-dollar bill. The hundred-dollar bill will disappear and [the sand] is still there to support you. (Anonymous 14, July 2015)

Based on these participant testimonies to the reassertion of Indigenous management and revitalization of cultural education via programs such as SEAS (http://www.emergingstewards.org/) and qqs (https://www.qqsprojects.org/), and the retention of core stewardship principles despite impacts of colonization and marine degradation, we are witnessing an escape from the trap initiated internally within partnering First Nations (Fig. 2). In this escape, positive interactions across youth education programs, active stewardship of local ecosystems, documentation and revival of IK, and reassertion of Indigenous management feed back to support both environmental restoration and the collective resurgence of Indigenous management rights.

\section{DISCUSSION}

We suggest that there was an extant social-ecological trap on the Central Coast of British Columbia, where the impacts of colonization and environmental degradation actively threaten IK and practices surrounding some marine resources but that this trap is transcendable. Collective efforts by First Nations involved in this study, including those of coauthors (SCT), are presently allowing First Nations to begin emerging from the imposed trap. This research into a focal species (yelloweye rockfish) revealed the interwoven nature of knowledge and lived experiences. Although our interviews focused on rockfish, most participants brought up colonization and environmental degradation, highlighting the ongoing impact of these experiences. These findings also reveal the inextricable role cultural context plays in ecological studies where Indigenous peoples are involved.

Although the framing of a social-ecological trap was valuable in highlighting the interlinked dynamics between colonization and resource depletion, we also found it to be problematic. The framing of a trap can be perceived to take away from the authority and legitimacy of the progress and internal governance systems led by Indigenous peoples, instead depicting them as powerless and vulnerable. We found the opposite to be true; despite the many external forces still working to diminish Indigenous peoples' authority, First Nations are actively shaping their future for the better. For example, Central Coast First Nations are actualizing the revival or retention of IK surrounding critical marine resources such as salmon (CCIRA 2010, Thornton et al. 2015), eulachon (Moody 2008), and herring (Kitasoo/Xai'xais First
Nation 2018). Restoration of this knowledge further corroborates our, and our First Nations partners', assertion that the socialecological trap is reversible. Additional concrete steps being taken by First Nations to combat the social-ecological trap include a new wave of cultural education programs for youth. Such programs enliven cultural tradition for Central Coast First Nations youth, returning them to cedar big houses, traditional knowledge, dance, and ceremony, and the ecosystems that Indigenous ancestors have stewarded for millennia.

A key difference in these findings compared with most other research into social-ecological traps was that the forces that created the trap were solely externally imposed rather than internally generated, and yet the trap was being overcome through internal means. Although several recent studies have focused on the external factors contributing to social-ecological traps (Enfors 2013, Boonstra et al. 2016, Long and Lake 2018), only one of these studies (Long and Lake 2018) suggested that the solution to the external perturbations was via internal processes. Other studies have largely assessed social-ecological traps in relation to community resilience (Folke 2006), arguing that amplifying feedbacks can occur between social and ecological degradation in resource management (Cinner 2011, Steneck et al. 2011, Kittinger et al. 2013) because of human responses to an ecological or social issue that exacerbate the issue. In these studies, the trap tends to be caused by the people affected by it (e.g., an impoverished community unsustainably extracts a local resource because of financial incentives), and external factors are not emphasized or reported. In contrast, on the Central Coast the trap was externally imposed, deliberately through colonization (Environics Research Group 2008), and through industrial fisheries (Jackson et al. 2001, Department of Fisheries and Oceans Canada 2015).

Historical and ecological evidence supports our findings. For example, ecological data gathered within the study region showed that yelloweye rockfish populations have experienced decreases in both size and abundance (McGreer and Frid 2017), and their biomass in B.C. is estimated to be at $18 \%$ of 1918 levels (Department of Fisheries and Oceans Canada 2015). Our research indicates that this reduction in biomass is due to a combination of colonial disruption of sustainable Indigenous practices and mismanagement of industrial fisheries. Other key species of importance, e.g., salmon, eulachon, herring, halibut, abalone, have similarly faced severe declines (Gresh et al. 2000, Hay and McCarter 2000, Levy 2006, Moody 2008). Because IK is place-based and dependent upon direct interactions with species, this knowledge may degrade in tandem with key resources (Turner and Turner 2008, Berkes 2012), though others have noted the adaptive capacity and dynamic nature of IK (Berkes 2012). The main social factor in the social-ecological trap in this system was colonialism, and more specifically loss of Indigenous governance rights and impacts of residential school systems, which forcibly removed children from family homes, and instituting them into a system that sought to eradicate First Nations' cultures and traditions (Royal Commission on Aboriginal Peoples 1996, Smith et al. 2005, de Leeuw 2009). Canada now recognizes that these schools served a role in the intentional severing of First Nations cultural and familial ties, IK, and lifeways (Environics Research Group 2008). Unfortunately, many international occurrences of systematic 
oppression of Indigenous peoples exists. In Australia and the U. S., Indigenous peoples were forcibly dispossessed of land, killed in conflicts with colonizers (Greer 1993, Brave Heart and DeBruyn 1998, Short 2003, Turner et al. 2013a), and forced into boarding schools that paralleled the residential schooling system in Canada (Brave Heart and DeBruyn 1998). These and countless other examples of international genocide and forced assimilation of Indigenous peoples resulted in the UN Declaration on the Rights of Indigenous Peoples (United Nations 2008), but the scars and modern manifestations of colonization remain.

The external and historical nature of the trap make mitigation daunting, yet we found that First Nations are impressively currently revitalizing their Indigenous principles and practices. Their responses included the following: (i) retention of core values of IK and local culture; (ii) active and powerful revival of IK; (iii) implementation of local language and cultural education; and (iv) revival of Indigenous stewardship practices. We interpret these responses as an act of social rebellion against the imposed forces working to trap coastal First Nations in the muting of their knowledge and devaluation of their management strategies. Rebellion against social-ecological traps is one of the categories suggested by Boonstra et al. (2016), characterized by collective motivation to escape the conditions of the trap and a refusal to accept the status quo, despite the continuing existence of detrimental trap features. This response type is relatively uncommon in the literature (Boonstra et al. 2016).

Several limitations became evident during the study, some of which are echoed in other social research and are detailed elsewhere (Huntington 1998, Drew 2005, Clark 2008, Eckert et al. 2018). Our results emerged from analysis of questions related to yelloweye rockfish, and interview participants were selected based on their experience in fishing for this species. Thus, key general knowledge holders, who likely possess greater depths of IK surrounding critical marine species other than rockfish, were not targeted as participants in interviews. Therefore, our conclusions regarding the state of IK surrounding yelloweye rockfish represent a subset of First Nations experiences and knowledge. However, we reflect that the emergence of these themes outside of targeted questions speaks to their importance. Finally, because this study targeted harvesters with $20+$ years' experience fishing yelloweye rockfish, responses largely do not represent the knowledge or perspective of rising generations of children and young adults within Central Coast First Nations. This generation, like many before them, has evidenced an awareness and commitment to Indigenous cultures, and is building and implementing cultural revitalization and engaging in resource management as part of a growing wave of Indigenous resurgence.

\section{CONCLUSION}

We suggest that the depth of stewardship values and local knowledge evidenced by First Nation participants and partners is the foundation for cultural revival and that Indigenous governments and management practices are already mobilizing for cultural and biological conservation. Although we documented a muted quality to IK surrounding yelloweye rockfish, all participants remembered and honored the stewardship principle of limiting harvests to only what is needed, and most possessed a depth of local knowledge, e.g., about the size and abundance of yelloweye rockfish, abundance hot spots, historical changes to populations (Eckert et al. 2018). Thus, the core of many yelloweye-specific stewardship strategies and cultural teachings remains intact. These ubiquitous sustainability values reflect an Indigenous ethic, that life is to be respected and that waste is deplorable, that is echoed on the coast and beyond (Turner and Berkes 2006, Brown and Brown 2009). This ethos is witnessed repeatedly in First Nations and other Indigenous cultures and may represent a worldview that was fundamental to avoiding depletion of vital local resources (Turner and Atleo 1998, Turner et al. 2000, Berkes and Turner 2006, Brown and Brown 2009, Turner 2014). The retention of core stewardship ethos marks an act of social rebellion (Boonstra et al. 2016) by coastal First Nations against the imposed trap spurred by colonialism, loss of governance rights, and externally driven environmental degradation. Thus, continued focus by partner Nations toward mobilizing the stories and customs that community members do recall, and that stewardship offices and community leaders have and continue to document, alongside supporting the upwelling cultural awareness evident in new generations, is working to allow this ethic to be again informed by traditional oral stories and ceremonies for species such as yelloweye rockfish.

We suggest that supporting First Nations' ongoing work to overcome the social-ecological trap needs to involve (1) recovery of depleted resources, and (2) reinvigorating Indigenous governance practices. First, recovery of resources is paramount given the interconnectedness of First Nations' culture, IK, and the quality of surrounding environment and resources (Turner and Berkes 2006, Berkes 2012). The most appropriate ecosystem recovery approaches will be context-specific, but could include strategies such as marine protected areas (MPAs) and improved fisheries management where First Nations have primary authority. Recognizing the governance authority by First Nations means that colonial governments must share or release their claimed jurisdiction. Studies suggest that the implementation of MPAs and fishing closures is strengthened when local communities are directly involved with the creation, implementation, and governance of marine conservation and management plans (Johannes 2002, Thornton and Maciejewski Scheer 2012).

Second, achieving simultaneous success in cultural resurgence and marine species recovery requires continuing work to recognize and support revitalization of Indigenous management rights on a local and global scale. Recognizing Indigenous title and governance rights to manage traditional territories will not only actively draw upon the IK and governing bodies of coastal First Nations, but will also allow for fisheries management to respond to local observations of declines (Frid et al. 2016, Eckert et al. 2018). At the forefront of reviving Indigenous marine management rights is the CCIRA, a collaborative nonprofit organization led by the four partnering Nations (Heiltsuk, Kitasoo/Xai'xais, Wuikinuxv, and Nuxalk) involved in this project, which seeks to inform resource management through a combination of independently collected ecological research, and the local and traditional knowledge of member Nations (CCIRA 2016). CCIRA, which recognizes that the collective goal of involved Nations is to preserve resources and ecosystems for the benefit of future generations, has facilitated First Nations leadership in comprehensive marine use planning within their 
ancestral territories. Recognizing the value of MPA planning and implementation for species conservation, the Wuikinuxv, Nuxalk, Kitasoo/Xai'xais, and Heiltsuk have proposed MPAs in their Central Coast marine use plan (CCIRA 2010), and are now engaged as recognized governments in MPA planning in collaboration with the provincial government (MaPP 2015) and federal government (MPA Network: BC Northern Shelf 2016). Implementing these plans at a federal level in Canada, alongside considering the independent species surveys and traditional knowledge surveys developed by CCIRA (Frid et al. 2016, Eckert et al. 2018) provides a way forward in Indigenous cultural resurgence and marine conservation that would move beyond the identified social-ecological trap. Implementation of such marine planning through joint management is certainly possible, as evidenced by the recently created Gwaii Haanas National Marine Conservation Area Reserve and Haida Heritage site. The site, established in 2010, is managed by both the Government of Canada and the Haida Nation and reflects a recognized need by both parties to protect ecosystem and resources of cultural importance (Parks Canada 2016). Although CCIRA provides a positive opportunity toward Indigenous management reassertion, it is notable that First Nations' territory and management rights have, in the last several decades, been won by Indigenous nations in Canada primarily through extensive and expensive legal cases, in which the onus of proof is placed disproportionately upon Indigenous nations (e.g. Delgamuukw v British Columbia 1997 , Tsilhqot'in Nation v. British Columbia, 2014).

This applied research, in partnership with four First Nations on B.C.'s Central Coast, revealed valuable insights into a socialecological trap faced by Indigenous peoples here and elsewhere and, importantly, that involved Nations have identified and are enacting ways to move beyond said trap. Indigenous peoples are forging ways forward through a strategy of continued tenacious focus on cultural revival and the active recovery of degraded species and habitats: an impressive feat of rebellion given the continuing impacts of colonization and environmental degradation enacted by external drivers. We, and another recent paper (Long and Lake 2018), suggest widespread and official recognition of inherent Indigenous management rights, and the reassertion of these rights through federally recognized traditional management measures, as a means of overcoming the social-ecological trap and simultaneously affirming Indigenous peoples' rights and management, alongside marine species conservation.

Responses to this article can be read online at: http://www.ecologyandsociety.org/issues/responses. php/10417

\section{Acknowledgments:}

First and absolutely foremost, we thank the Kitasoo/Xai'xais, Wuikinuxv, Heiltsuk, and Nuxalk Nations whose energy, knowledge, generosity, and support made this work possible. We are grateful to all those who participated in the study and whose observations, contributions, and willingness to offer their time and knowledge constitute our data, as well as those stewardship directors and stewardship staff who facilitated this work. We also thank the Tallio family for contributing anecdotes from their proprietary Q'umukwa story. Megan Moody, Nicole Kaechele, Dr. Alejandro Frid, Dr. Chris Darimont, and Kelly Brown provided specific edits and formative feedback that were critical for guiding the document in its final stages, and Peter Siwallace, Danielle Shaw, Barry Edgar, and Doug Neasloss also contributed substantial time and support to this project. Additionally, we wish to acknowledge the financial support provided by The Marine Environmental Observation Prediction and Response Network (MEOPAR), the Social Sciences and Humanities Research Council (SSHRC), National Sciences and Engineering Research Council (NSERC), The National Geographic Society, and Ocean Canada.

\section{LITERATURE CITED}

Adams, W. M., and M. Mulligan. 2003. Decolonizing nature: strategies for conservation in a post-colonial era. Earthscan, London, UK.

Berkes, F. 2012. Sacred ecology: traditional ecological knowledge and management systems. Routledge, London, UK. http://dx.doi. org/10.4324/9780203123843

Berkes, F., J. Colding, and C. Folke. 2000. Rediscovery of traditional ecological knowledge as adaptive management. Ecological Applications 10(5):1251-1262. http://dx.doi. org/10.1890/1051-0761(2000)010[1251:ROTEKA]2.0.CO;2

Berkes, F., and N. J. Turner. 2006. Knowledge, learning and the evolution of conservation practice for social-ecological system resilience. Human Ecology 34(4):479-494. http://dx.doi. org/10.1007/s10745-006-9008-2

Boonstra, W. J., E. Björkvik, L. J. Haider, and V. Masterson. 2016. Human responses to social-ecological traps. Sustainability Science 11(6):877-889. http://dx.doi.org/10.1007/s11625-016-0397$\underline{x}$

Boonstra, W. J., and F. W. De Boer. 2014. The historical dynamics of social-ecological traps. AMBIO 43(3):260-274. http://dx.doi. org/10.1007/s13280-013-0419-1

Brave Heart, M. Y. H., and L. M. DeBruyn. 1998. The American Indian holocaust: healing historical unresolved grief. American Indian and Alaska Native Mental Health Research 8(2):60-82. http://dx.doi.org/10.5820/aian.0802.1998.60

Brown, F., and K. Brown. 2009. Staying the course, staying alive. Biodiversity BC, Victoria, British Columbia, Canada.

Butler, C. F., and C. R. Menzies. 2007. Traditional ecological knowledge and Indigenous tourism. Pages 15-27 in R. Butler and T. Hinch, editors. Tourism and Indigenous peoples: issues and implications. Elsevier, Oxford, UK. http://dx.doi.org/10.1016/ B978-0-7506-6446-2.50007-7

Central Coast Indigenous Resource Alliance (CCIRA). 2010. Central coast First Nations marine use plan - executive summary. CCIRA, Campbell River, British Columbia, Canada. [online] URL: http://ccira.ca/media/documents/pdf/central-coast-executivesummary-email.pdf

Central Coast Indigenous Resource Alliance (CCIRA). 2016. Central Coast Indigenous Resource Alliance. CCIRA, Campbell 
River, British Columbia, Canada. [online] URL: https://www. ccira.ca

Chapin, F. S., S. R. Carpenter, G. P. Kofinas, C. Folke, N. Abel, W. C. Clark, P. Olsson, D. M. Stafford Smith, B. Walker, O. R. Young, F. Berkes, R. Biggs, J. M. Grove, R. L. Naylor, E. Pinkerton, W. Steffen, and F. J. Swanson. 2010. Ecosystem stewardship: sustainability strategies for a rapidly changing planet. Trends in Ecology and Evolution 25(4):241-249. http://dx. doi.org/10.1016/j.tree.2009.10.008

Cinner, J. E. 2011. Social-ecological traps in reef fisheries. Global Environmental Change 21(3):835-839. http://dx.doi.org/10.1016/ j.gloenvcha.2011.04.012

Cinner, J. E., and S. Aswani. 2007. Integrating customary management into marine conservation. Biological Conservation 140(3-4):201-216. http://dx.doi.org/10.1016/j.biocon.2007.08.008

Cisneros-Montemayor, A. M., D. Pauly, L. V. Weatherdon, and Y. Ota. 2016. A global estimate of seafood consumption by coastal Indigenous peoples. PLOS ONE 11(12):e0166681. http://dx.doi. org/10.1371/journal.pone.0166681

Clark, T. 2008. "We're over-researched here!": exploring accounts of research fatigue within qualitative research engagements. Sociology 42(5):953-970. http://dx.doi.org/10.1177/0038038508094573

Colding, J., and C. Folke. 2001. Social taboos: invisible systems of local resource management and biological conservation. Ecological Applications 11(2):584-600.

de Leeuw, S. 2009. 'If anything is to be done with the Indian, we must catch him very young': colonial constructions of Aboriginal children and the geographies of Indian residential schooling in British Columbia, Canada. Children's Geographies 7(2):123-140. http://dx.doi.org/10.1080/14733280902798837

Department of Fisheries and Oceans Canada. 2015. Stock assessment for the outside population of yelloweye rockfish (Sebastes ruberrimus) in British Columbia, Canada for 2014. DFO Canadian Science Advisory Secretariat Science Advisory Report 2015/060.

Drew, J. A. 2005. Use of traditional ecological knowledge in marine conservation. Conservation Biology 19(4):1286-1293. http://dx.doi.org/10.1111/j.1523-1739.2005.00158.x

Eckert, L. E., N. C. Ban, A. Frid, and M. McGreer. 2018. Diving back in time: extending historical baselines for yelloweye rockfish with Indigenous knowledge. Aquatic Conservation: Marine and Freshwater Ecosystems 28(1):158-166. http://dx.doi.org/10.1002/ aqc. 2834

Enfors, E. 2013. Social-ecological traps and transformations in dryland agro-ecosystems: using water system innovations to change the trajectory of development. Global Environmental Change 23(1):51-60. http://dx.doi.org/10.1016/j.gloenvcha.2012.10.007

Environics Research Group. 2008. Final report: 2008 national benchmark survey. Prepared for Indian Residential Schools Resolution Canada and the Truth and Reconciliation Commission. Environics Research Group, Ottawa, Ontario, Canada.

Folke, C. 2006. Resilience: the emergence of a perspective for social-ecological systems analyses. Global Environmental Change 16(3):253-267. http://dx.doi.org/10.1016/j.gloenvcha.2006.04.002
Frid, A., M. McGreer, D. R. Haggarty, J. Beaumont, and E. J. Gregr. 2016. Rockfish size and age: the crossroads of spatial protection, central place fisheries and Indigenous rights. Global Ecology and Conservation 8:170-182. http://dx.doi.org/10.1016/j. gecco.2016.09.008

Greer, S. 1993. Australian Aboriginal societies and heritage. Pages 187-204 in N. Loos and T. Osanai, editors. Indigenous minorities and education: Australian and Japanese perspectives of their Indigenous peoples, The Ainu, Aborigines and Torres Straight Islanders. Sangusha Publishing, Tokyo, Japan.

Gresh, T., J. Lichatowich, and P. Schoonmaker. 2000. An estimation of historic and current levels of salmon production in the northeast Pacific ecosystem: evidence of a nutrient deficit in the freshwater systems of the Pacific Northwest. Fisheries 25 (1):15-21. http://dx.doi.org/10.1577/1548-8446(2000)025<0015: $\underline{\mathrm{AEOHAC}}>2.0 . \mathrm{CO} ; 2$

Groesbeck, A. S., K. Rowell, D. Lepofsky, and A. K. Salomon. 2014. Ancient clam gardens increased shellfish production: adaptive strategies from the past can inform food security today. PLoS ONE 9(3):e91235. http://dx.doi.org/10.1371/journal. pone.0091235

Hay, D. E., and P. B. McCarter. 2000. Status of the eulachon Thaleichthys pacificus in Canada. Canadian Stock Assessment Secretariat Research Document 2000/145. Fisheries and Oceans Canada, Science Branch, Pacific Biological Station, Nanaimo, British Columbia, Canada.

Hughes, T. P., D. R. Bellwood, C. Folke, R. S. Steneck, and J. Wilson. 2005. New paradigms for supporting the resilience of marine ecosystems. Trends in Ecology and Evolution 20 (7):380-386. http://dx.doi.org/10.1016/j.tree.2005.03.022

Huntington, H. P. 1998. Observations on the utility of the semidirective interview for documenting traditional ecological knowledge. Arctic 51(3):237-242. http://dx.doi.org/10.14430/ $\underline{\operatorname{arctic} 1065}$

Huntington, H. P. 2000. Using traditional ecological knowledge in science: methods and applications. Ecological Applications 10 (5):1270-1274. http://dx.doi.org/10.1890/1051-0761(2000)010[1270: UTEKIS]2.0.CO;2

Jackson, J. B., M. X. Kirby, W. H. Berger, K. A. Bjorndal, L. W. Botsford, B. J. Bourque, R. H. Bradbury, R. Cooke, J. Erlandson, J. A. Estes, T. P. Hughes, S. Kidwell, C. B. Lange, H. S. Lenihan, J. M. Pandolfi, C. H. Peterson, R. S. Steneck, M. J. Tegner, and R. R. Warner. 2001. Historical overfishing and the recent collapse of coastal ecosystems. Science 293(5530):629-637. http://dx.doi. org/10.1126/science.1059199

Johannes, R. E. 1978. Traditional marine conservation methods in Oceania and their demise. Annual Review of Ecology and Systematics 9(1978):349-364. http://dx.doi.org/10.1146/annurev. es.09.110178.002025

Johannes, R. E. 1998. Government supported, village-based management of marine resources in Vanuatu. Ocean \& Coastal Management 40:165-186. http://dx.doi.org/10.1016/S0964-5691 (98)00046-5

Johannes, R. E. 2002. The renaissance of community-based marine resource management in Oceania. Annual Review of 
Ecology and Systematics 33(1):317-340. http://dx.doi.org/10.1146/ annurev.ecolsys.33.010802.150524

Kitasoo/Xai'xais First Nation. 2018. Kitasoo/Xai'xais management plan for Pacific herring. Kitasoo/Xai'xais First Nation, Klemtu, British Columbia, Canada.

Kittinger, J. N., E. M. Finkbeiner, N. C. Ban, K. Broad, M. H. Carr, J. E. Cinner, S. Gelcich, M. L. Cornwell, J. Z. Koehn, X. Basurto, R. Fujita, M. R. Caldwell, and L. B. Crowder. 2013. Emerging frontiers in social-ecological systems research for sustainability of small-scale fisheries. Current Opinion in Environmental Sustainability 5(3-4):352-357. http://dx.doi. org/10.1016/j.cosust.2013.06.008

Lepofsky, D., and M. Caldwell. 2013. Indigenous marine resource management on the Northwest Coast of North America. Ecological Processes 2(1):12. http://dx.doi.org/10.1186/2192-1709-2-12

Levy, D. 2006. BC Sockeye salmon population declines: probable causes and recommended response strategies. Sierra Club of Canada, B.C. Chapter, Victoria, British Columbia, Canada.

Long, J. W., and F. K. Lake. 2018. Escaping social-ecological traps through tribal stewardship on national forest lands in the Pacific Northwest, United States of America. Ecology And Society 23 (2):10. http://dx.doi.org/10.5751/ES-10041-230210

MaPP. 2015. Central Coast Marine Plan. MaPP, British Columbia, Canada.

Matthews, D. L., and N. J. Turner. 2017. Ocean cultures: Northwest Coast ecosystems and Indigenous management systems. Pages 169-206 in P. S. Levin and M. R. Poe, editors. Conservation for the Anthropocene Ocean. Elsevier, London, UK.

McGreer, M., and A. Frid. 2017. Declining size and age of rockfish (Sebastes spp.) inherent to Indigenous cultures of Pacific Canada. Ocean and Coastal Management 145:14-20. http://dx. doi.org/10.1016/j.ocecoaman.2017.04.019

Menzies, C. R., and C. F. Butler. 2007. Returning to selective fishing through Indigenous fisheries knowledge: the example of K'moda, Gitxaala Territory. American Indian Quarterly 31 (3):441-464. http://dx.doi.org/10.1353/aiq.2007.0035

Moody, M. F. 2008. Eulachon past and present. Dissertation. University of British Columbia, Vancouver, British Columbia, Canada.

MPA Network: BC Northern Shelf. 2016. What's happening? Introducing the Northern Shelf Bioregion MPA Network. MPA Network: BC Northern Shelf, British Columbia, Canada. [online] URL: http://mpanetwork.ca/bcnorthernshelf/whats-happening/

Parks Canada. 2016. Gwaii Haanas National Park Reserve, National Marine Conservation Area Reserve, and Haida Heritage Site. Parks Canada, Gatineau, Québec, Canada. [online] URL: http://www.pc.gc.ca/eng/pn-np/bc/gwaiihaanas/plan/plan1.aspx

Pauly, D., V. Christensen, J. Dalsgaard, R. Froese, and F. Torres. 1998. Fishing down marine food webs. Science 279 (5352):860-863. http://dx.doi.org/10.1126/science.279.5352.860

Pinkerton, E. W. 1994. Local fisheries co-management: a review of international experiences and their implications for salmon management in British Columbia. Canadian Journal of Fisheries and Aquatic Sciences 51(10):2363-2378. http://dx.doi.org/10.1139/ f94-238

Royal Commission on Aboriginal Peoples. 1996. Report of the Royal commission on aboriginal peoples, perspectives and realities, Vol.4. Royal Commission on Aboriginal Peoples, Ottawa, Ontario, Canada.

Short, D. 2003. Reconciliation, assimilation, and the Indigenous peoples of Australia. International Political Science Review 24 (4):491-513. http://dx.doi.org/10.1177/01925121030244005

Slaney, T. L., K. D. Hyatt, T. G. Northcote, and R. J. Fielden. 1996. Status of anadromous salmon and trout in British Columbia and Yukon. Fisheries 21(10):20-35. http://dx.doi. org/10.1577/1548-8446(1996)021<0020:SOASAT $>2.0$. CO;2

Smith, D., C. Varcoe, and N. Edwards. 2005. Turning around the intergenerational impact of residential schools on Aboriginal People: implications for health policy and practice. Canadian Journal of Nursing Research 37:38-60.

Smith, L. T. 1999. Decolonizing methodologies: research and Indigenous peoples. Zed Books, London, UK.

Steneck, R. S. 2009. Marine conservation: moving beyond Malthus. Current Biology 19(3):117-119. http://dx.doi.org/10.1016/ j.cub.2008.12.009

Steneck, R. S., T. P. Hughes, J. E. Cinner, W. N. Adger, S. N. Arnold, F. Berkes, S. A. Boudreau, K. Brown, C. Folke, L. Gunderson, P. Olsson, M. Scheffer, E. Stephenson, B. Walker, J. Wilson, and B. Worm. 2011. Creation of a gilded trap by the high economic value of the Maine lobster fishery. Conservation Biology 25(5):904-912. http://dx.doi.org/10.1111/j.1523-1739.2011.01717. $\underline{\mathrm{X}}$

Thornton, T., D. Deur, and H. Kitka. 2015. Cultivation of salmon and other marine resources on the Northwest Coast of North America. Human Ecology 43(2):189-199. http://dx.doi.org/10.1007/ s10745-015-9747-Z

Thornton, T. F., and A. Maciejewski Scheer. 2012. Collaborative engagement of local and traditional knowledge and science in marine environments: a review. Ecology and Society 17(3):8. http://dx.doi.org/10.5751/ES-04714-170308

Turner, N., D. Deur, and D. Lepofsky. 2013b. Plant management systems of British Columbia's first peoples. BC Studies 179:107.

Turner, N. J. 2014. Ancient pathways, ancestral knowledge: ethnobotany and ecological wisdom of Indigenous peoples of northwestern North America. McGill Queen's University Press, Montreal, Québec, Canada.

Turner, N. J., and E. R. Atleo (Chief Umeek). 1998. Pacific North American First Peoples and the environment. Pages 105-124 in H. Coward, editor. Environment and development values in the Pacific. Center for Studies in Religion and Society, University of Victoria, British Columbia, Canada, and State University of New York, Albany, New York, USA.

Turner, N. J., and F. Berkes. 2006. Coming to understanding: developing conservation through incremental learning in the Pacific Northwest. Human Ecology 34:495-513. http://dx.doi. org/10.1007/s10745-006-9042-0 
Turner, N. J., M. B. Ignace, and R. Ignace. 2000. Traditional ecological knowledge and wisdom of Aboriginal Peoples in British Columbia. Ecological Applications 10(5):1275-1287. http://dx.doi.org/10.1890/1051-0761(2000)010[1275:TEKAWO]2.0. $\underline{\mathrm{CO} ; 2}$

Turner, N. J., M. Plotkin, and H. V. Kuhnlein. 2013a. Global environmental challenges to the integrity of Indigenous peoples' food systems. Pages 22-38 in H. V. Kuhnlein, B. Erasmus, D. Spigelski, and B. Burlingame, editors. Indigenous peoples' food systems \& well-being: interventions \& policies for healthy communities. Food and Agricultural Organization of the United Nations and Centre for Indigenous Peoples' Nutrition and Environment, Montreal, Québec, Canada, and Rome, Italy.

Turner, N. J., and K. L. Turner. 2008. "Where our women used to get the food": cumulative effects and loss of ethnobotanical knowledge and practice: case study from coastal British Columbia. Botany 86(2):103-115. http://dx.doi.org/10.1139/ $\underline{\mathrm{B} 07-020}$

United Nations. 2008. United Nations Declaration on the Rights of Indigenous Peoples. Resolution 61/295. United Nations General Assembly, New York, New York, USA.

Worm, B., R. Hilborn, J. K. Baum, T. A. Branch, J. S. Collie, C. Costello, M. J. Fogarty, E. Fulton, J. Hutchings, S. Jennings, O. P. Jensen, H. K. Lotze, P. M. Mace, T. R. McClanahan, C. Minto, S. R. Palumbi, A. M. Parma, D. Ricard, A. Rosenberg, R. Watson, and D. Zeller. 2009. Rebuilding global fisheries. Science 325:578-585. http://dx.doi.org/10.1126/science.1173146 